\title{
Patrimonio arquitectónico y desigualdad de género en la ciudad de Salta
}

\author{
Cinthia Natalia Gonza \\ Universidad Nacional de Salta, Consejo Nacional de Investigaciones Científicas \\ y Técnicas, Argentina \\ cinthianata@gmail.com
}

Recibido: 10/9/2018 / Aceptado: 3/11/2018

doi: 10.26439/contratexto2019.n031.3895

\begin{abstract}
Resumen. El artículo interroga y analiza algunos elementos del patrimonio arquitectónico de la ciudad de Salta, Argentina, en clave genealógica y desde los estudios de género. El patrimonio histórico es entendido como un dispositivo que articula un tipo de racionalidad que ofrece una presencia subordinada de las mujeres en el espacio público. La problematización del mismo resulta un desafío y un punto elemental para pensar y configurar ciudades más igualitarias.
\end{abstract}

Palabras clave: género / ciudad / patrimonio arquitectónico / comunicación / dispositivo

\section{Architectural heritage and gender inequality in the city of Salta}

Авstract. The article questions and analyzes some elements of the architectural heritage of the city of Salta, Argentina, from the genealogical perspective and gender studies. The historical heritage is understood as a device that articulates a type of rationality showing subordination of women in the public space. This problem turns out to be a challenge and a focal point at the moment of thinking and creating more egalitarian cities.

Keywords: gender / city / architectural heritage / communication / device 
Es preciso que la ciudad mantenga con el resto del territorio una relación estética y simbólica, ella debe ser el ordenamiento mismo del territorio. [...] Es menester así mismo que la capital mantenga un papel moral y difunda hasta los últimos confines del territorio todo lo que sea necesario imponer a la gente en materia de conducta y maneras de obrar.

Michel Foucault (2016)

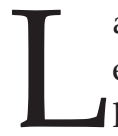
as ciudades se perciben y experimentan de maneras muy distintas según el género, la edad, las condiciones socioeconómicas, la raza, la religión y las condiciones físicas. Los modelos ideológicos presentes en la vida cotidiana dificultan hablar de prácticas y accesos igualitarios a la ciudad (McDowell, 2000). Los espacios vividos estructuran y al mismo tiempo son resultado de relaciones de poder, capaces de establecer y definir los límites sociales y espaciales que determinan qué cuerpos, qué identidades, qué sujetos pertenecen a un lugar y quiénes quedan excluidos, subordinados, invisibilizados.

En esta dirección, las ciudades se construyen ignorando las experiencias, las historias y las necesidades específicas de las mujeres. La planificación urbanística, su enseñanza y profesionalización han sido mayoritariamente terreno dominado por el colectivo masculino, que ha construido una visión del espacio urbano homogénea y universal aunque este se encuentre centrado en sus propios intereses y preocupaciones. Como señala Soto Villagrán (2011), el espacio urbano toma el punto de vista masculino como criterio interpretativo y norma para explicar el funcionamiento espacial dentro de las ciudades.

Pero, ¿cómo aprehender esta desigualdad si la ciudad se nos presenta como un espacio imparcial y en apariencia neutro? Aproximándose a una de las posibles respuestas, este artículo propone el análisis del patrimonio histórico de la ciudad de Salta ${ }^{1}$ a partir de algunos elementos del concepto de dispositivo de Michel Foucault (1987, 2016). El análisis buscará la comprensión de las desigualdades de género manifiestas en la ciudad, entendiendo el patrimonio histórico - “lo recibido del padre" - como un dispositivo que articula un tipo de racionalidad que, si bien no invisibiliza completamente a las mujeres, ofrece una presencia subordinada de

1 Salta es una de las 23 provincias de la República Argentina. Está ubicada al noroeste del país, en la región conocida como el Noroeste Argentino (NOA). Limita al norte con la provincia de Jujuy, Bolivia y Paraguay (hacia el noreste), al este con Formosa y Chaco, al sur con Santiago del Estero, Tucumán y Catamarca, y al oeste con Chile. Cuenta con una superficie de 155488 km². En el 2016 la ciudad de Salta alcanzó la cifra de 618000 habitantes. Situada en el fértil Valle de Lerma, es un importante centro comercial y nudo en las comunicaciones entre Argentina, Chile y Bolivia. 
ellas en este espacio, por fuera de toda figura y acción política. El trabajo analizará el patrimonio arquitectónico en su capacidad de ordenar como un texto homogéneo los elementos dispersos (tangibles y no tangibles) presentes en la ciudad, en su vínculo con ciertos relatos históricos que jerarquizan ciertos actores y hechos del pasado en el presente, en su asociación con la identidad y en tanto sistema rígido, casi inmutable, de un orden simbólico, político y social capaz de asegurar la permanencia y la continuidad de ciertos valores, que construyen y constriñen una versión hegemónica de Salta como una ciudad colonial.

\section{Los dispositivos}

La palabra "dispositivo" aparece en la constelación foucaultiana durante los años setenta, junto con el desarrollo de lo que este pensador denominó "gubernamentalidad" o "gobierno de los hombres". Podríamos decir que estos términos son fundamentales en el desarrollo de una etapa que se caracteriza por una fuerte impronta analítico-política de las instituciones de poder.

Una genealogía del término dispositivo nos lleva a fines de los años sesenta, época en la que Michel Foucault escribe La arqueología del saber (2018). Allí, para delimitar el objeto de su investigación, Foucault emplea un término epistemológicamente cercano a dispositivo: positividad. Rastreando este término se llega a algunos de los ensayos de Jean Hyppolite. Este filósofo - quien fue maestro de Foucault en el liceo Henri IV y luego en la Escuela Normal- dedicó gran parte de sus escritos al análisis de la obra de Hegel. En "La positividad de la religión cristiana", destaca "destino" y "positividad" como conceptos clave del pensamiento hegeliano. El término positividad posee un lugar propio en Hegel en la oposición "religión natural" y "religión positiva"; mientras la primera refiere a la relación inmediata de la razón humana con lo divino, la segunda hace alusión a un conjunto de creencias, reglas y ritos que le son impuestas a una sociedad determinada en un determinado momento histórico. En este sentido Hyppolite muestra cómo entre naturaleza y positividad se corresponde la dialéctica entre libertad y coerción, entre razón e historia. Agamben (2016) considera que es esta lectura de Hyppolite la que de alguna manera nutre las nociones de positividad y, más tarde, de dispositivo en Foucault, considerando el elemento histórico como un aspecto central en ellas.

Si bien no se encuentran en la constelación del pensamiento de Foucault definiciones clásicas de los términos técnicos que emplea, en la mayoría de los casos los conceptos se construyen a lo largo y ancho de sus producciones. En 1977 este pensador ofrece una suerte de definición del término dispositivo en situación de entrevista: 
Lo que trato de identificar con este término es ante todo un conjunto heterogéneo que incluye discursos, instituciones, estructuras arquitectónicas, leyes, decisiones regulativas, medidas administrativas, enunciados científicos, proposiciones filosóficas, morales, filantrópicas, en definitiva, tanto lo dicho como lo no dicho, he ahí los elementos de un dispositivo. El dispositivo es la red que se establece entre estos elementos. (Cit. en Agamben, 2016, p. 8)

Otra de las características de los dispositivos tiene que ver con la forma en que operan: estos buscan influir sobre acontecimientos específicos de la realidad En esta dirección se entenderá que los dispositivos son formaciones históricas que tienen como función esencial responder a una urgencia. En "Seguridad, territorio y población" se ofrece un claro ejemplo de la forma en la que operan los dispositivos de seguridad sobre el problema de la escasez durante los el siglos xviI y xviII en Europa:

Un dispositivo que conectado a la realidad de esas oscilaciones (escasez/abundancia de grano) haga por medio de una serie de vinculaciones con otros elementos de la realidad que ese fenómeno, sin perder nada de su realidad, quede poco a poco compensado, frenado y limitado y en última instancia anulado. (Foucault, 2016, p. 57)

Se entiende entonces que los dispositivos poseen una "naturaleza" estratégica que manipula las relaciones de fuerzas mediante una intervención de tipo racional. Inscritos siempre en una relación de poder, los dispositivos se encuentran ligados a los límites de un saber del cual derivan y por el cual son condicionados (Agamben, 2016, p. 8). Un dispositivo es un conjunto de estrategias de relaciones de fuerza que condicionan ciertos tipos de saber y son condicionados por este. El término dispositivo nombra aquello en lo cual y a través de lo cual se realiza una actividad "pura" de gobierno, lo que implica un proceso de subjetivación, es decir, los dispositivos producen cierto tipo de subjetividades, cierto tipo de sujetos.

\section{Patrimonización de la desigualdad}

A fuerza de resumen se pueden destacar tres aspectos característicos de los dispositivos que señalaremos a continuación en conversación directa con el análisis del patrimonio histórico de la ciudad de Salta. El primero de ellos señala que los dispositivos constituyen un grupo heterogéneo que incluye tanto lo lingüístico como lo no lingüístico, es decir, instituciones, discursos, edificios, leyes, medidas policiales, proposiciones científicas, morales, etcétera. Un dispositivo es la red que se establece entre estos elementos. En segundo lugar nos referimos a la función estratégica de los dispositivos, inscrita siempre en una relación de poder y, finalmente, los dispositivos como resultado del cruce entre relaciones de poder-saber que crean subjetividades específicas (Agamben, 2016; Deleuze, 2015). 
Los dispositivos surgen ante una urgencia y establecen una red estratégica entre un grupo heterogéneo de elementos: podría decirse que las políticas dirigidas a la conservación-restauración de ciertos edificios del casco histórico y la construcción de arquitecturas más recientes que producen el efecto de verdad de Salta como ciudad colonial (Foucault, 1987), emergen como una estrategia frente a una provincia que en los últimos años ha presentado los niveles de desocupación y pobreza más elevados del país. Ante esta urgencia u oscilación se alude a los beneficios del turismo que, se asocia con la generación de empleo y con mejoras en las condiciones de vida de la población local, para convertir esta actividad económica - junto con la minería-, en una de las principales actividades de la provincia y en una fuerte política de Estado. El Plan Turístico Maestro (2006-2016) sostiene que el turismo constituye uno de los "motores de la economía salteña" favoreciendo la "creación de nuevas fuentes de trabajo que se traducen en mejor calidad de vida para la sociedad" (Gobierno de la provincia de Salta, 2008, p. 6).

Si bien es cierto que la idea de Salta como ciudad colonial y turística comienza a ser asunto político a principios del siglo xx en la búsqueda de una expresión de carácter "nacional" basada en los "orígenes" hispánicos (Flores Klaric, 2010), solo analizaremos aquí el periodo que comprende los últimos 15 años. En este, la historia, la estética, el arte, la arquitectura, las leyes, medidas policiales y jurídicas y toda una serie de políticas públicas se pondrán al servicio de la preservación, salvaguarda, protección, restauración y promoción del patrimonio arquitectónico y urbanístico de la provincia de Salta que según la Ley 7418, artículos 1 y 2, en sus "aspectos tangibles o intangibles, materiales o simbólicos definen la identidad y la memoria colectiva de los habitantes".

El 23 de noviembre del 2006 la cámara de diputados de la provincia de Salta sanciona la Ley 7418-05 (Boletín Oficial Salta, 2006) llamada Ley de Protección del Patrimonio Arquitectónico y Urbanístico de la Provincia de Salta. Esta ley nos permite observar la manera en la que se articula una política económica centrada en el desarrollo del turismo con una serie de diversas instituciones y saberes:

Art. 3.․․ Los bienes que integran el Patrimonio Arquitectónico y Urbanístico de la Provincia de Salta (PAUPS), son de carácter histórico, etnográfico, artístico, arquitectónico, urbanístico o paisajístico.

$[\ldots]$

Art. 13. ${ }^{\circ}$ El Área Técnica de la Comisión estará integrada por la Dirección General de Patrimonio Cultural dependiente del Ministerio de Educación, que oficiará como Asesoría permanente de la Comisión. También se podrán incorporar con carácter transitorio, representantes de las Asociaciones Profesionales, Universidades locales y/o nacionales y cualquier otro experto que a juicio de la Comisión o de la Dirección General de Patrimonio lo juzgue necesario. 


\section{$[\ldots]$}

Art. 23.․ La Comisión deberá elaborar un Plan Regulador para el desarrollo y conservación de los bienes declarados de interés arquitectónico y/o urbanístico en los términos de la presente ley. Dicho Plan deberá establecer las bases del ordenamiento territorial para el asentamiento poblacional, la infraestructura de servicios, sistemas de comunicación, transporte y accesibilidad, considerando el desarrollo turístico, productivo y sustentable.

Para el análisis del Plan Regulador se conformará el Consejo Asesor de Protección, que estará integrado por los representantes de los siguientes organismos:

a) Autoridades Municipales de las localidades implicadas.

b) Ministerio de la Producción y el Empleo.

c) Secretaría de la Gobernación de Turismo.

d) Otros organismos gubernamentales competentes.

e) Personas o entidades afines a la temática.

Una vez elaborado el Plan, la Comisión lo elevará al Poder Ejecutivo Provincial para su aprobación y puesta en funcionamiento. Las autoridades municipales emitirán la legislación necesaria para la aplicación del Plan Regulador.

Si bien del patrimonio arquitectónico - en tanto recurso primario de la industria del turismo- se espera la generación de renta y recursos, esta dimensión económica no posee un carácter predominante. Ya desde el siglo XvIII, la arquitectura adquiere una función ligada con los objetivos y técnicas de gobierno en las sociedades. Bajo esta función, la arquitectura interroga el espacio en función, por ejemplo, de cómo debe evitar las epidemias, las revueltas, promover una vida familiar conveniente y conforme a una moral (Foucault, 1987).

Los dispositivos se inscriben en una relación de poder. El patrimonio histórico es el resultado de un proceso de selección de ciertos referentes identitarios que se lleva a cabo en el presente, rescatando determinados elementos del pasado (Troncoso, 2013). Esta selección dirigida por determinados sectores del poder político, les permite hacer ver, decir y valer su versión de la identidad anulando la existencia de otras posibles selecciones y sus correspondientes versiones identitarias. Bien señala Gilles Deleuze:

Cada dispositivo tiene su régimen de luz, la manera en que ésta cae, se esfuma, se difunde, al distribuir lo visible y lo invisible, al hacer nacer o desaparecer el objeto que no existe sin ella. No es sólo pintura, sino que es también arquitectura. (Deleuze, 2015, p. 155) 
Al promocionar la capital salteña como ciudad turística suele destacarse la condición de ciudad colonial por sobre otros aspectos. A pesar de las numerosas transformaciones y modificaciones que sufrió la ciudad de Salta desde su fundación, su pasado colonial se pone de relieve por sobre cualquier otro pasado y sobre cualquier otro rasgo (Troncoso, 2013). La fachada de construcciones como el Convento de San Bernardo (1582), la Iglesia de San Francisco (1772) - aunque la influencia del estilo arquitectónico italiano aquí sea evidente-, el Cabildo (1780), la Catedral (1852) - donde también prevalece un estilo barroco italianoy exponentes de la arquitectura doméstica como las casas Arias Rengel (1752), Hernández (1780) y Leguizamón (1806), constituyen verdaderos emblemas del estilo arquitectónico colonial.

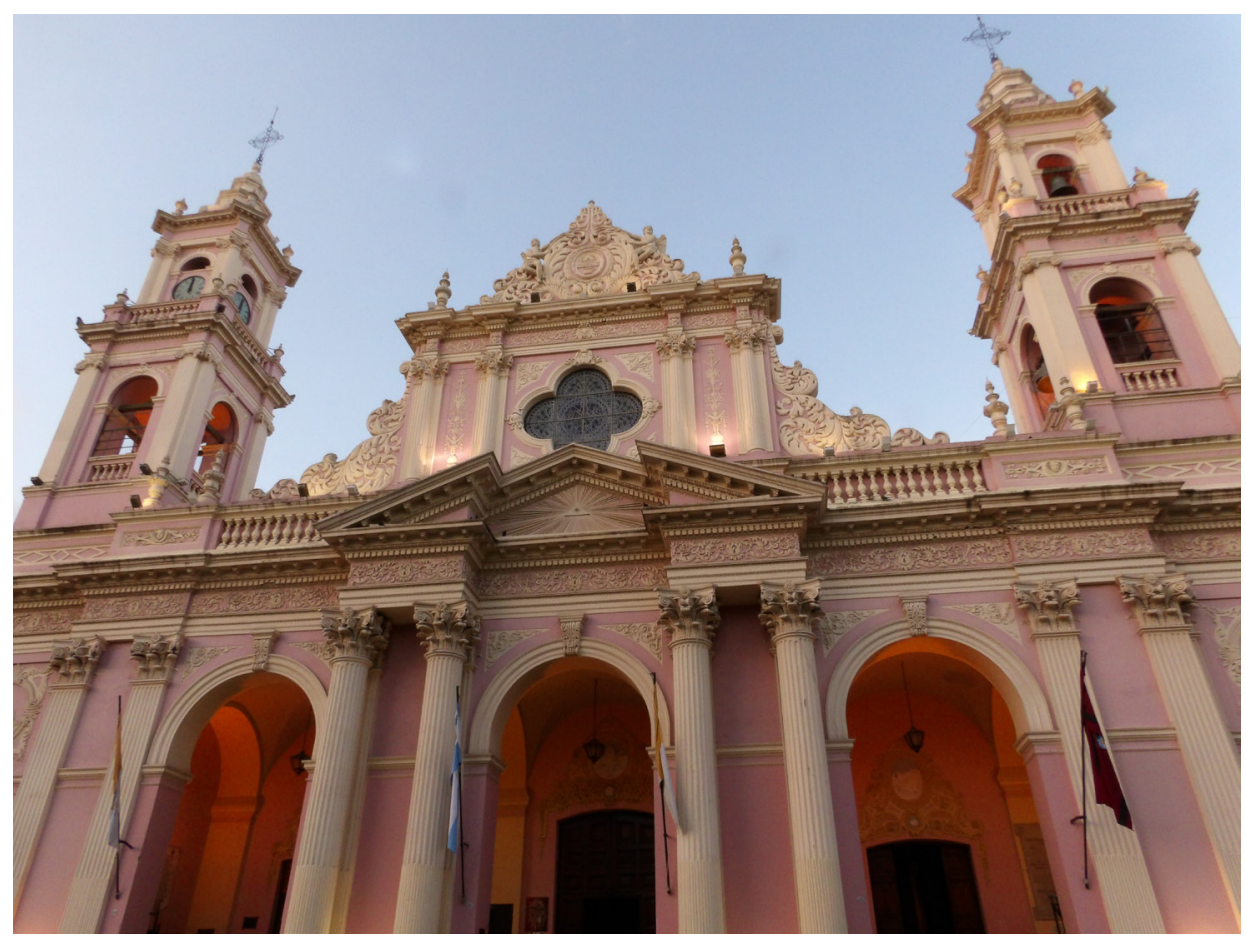

Figura 1. Catedral basílica de Salta Fotografía: Cinthia Natalia Gonza 


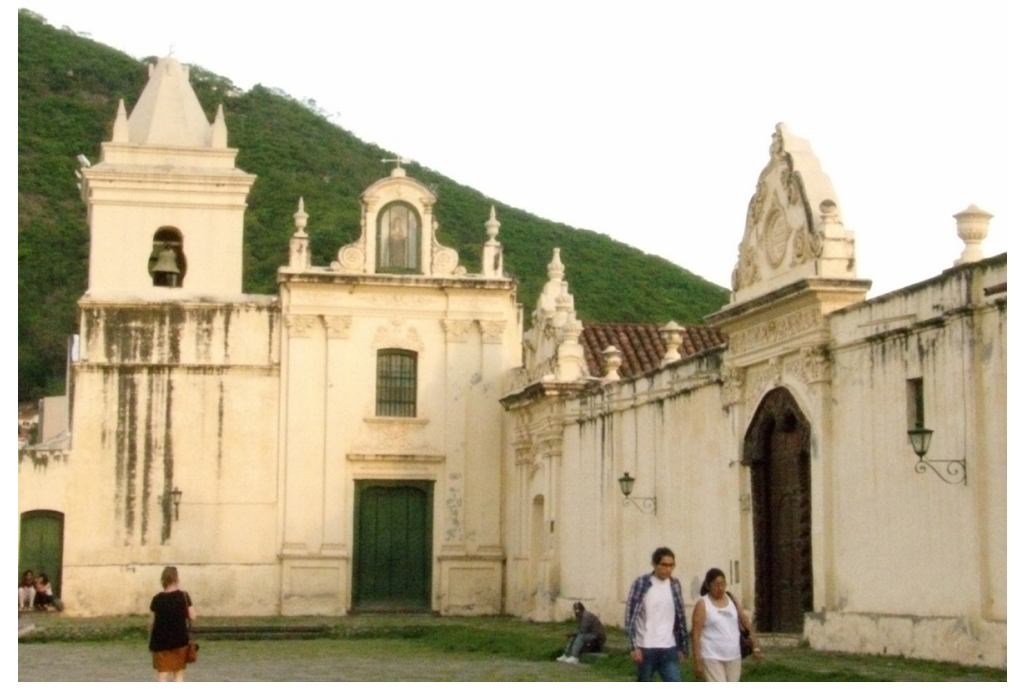

Convento San Bernardo

Fotografía: Cinthia Natalia Gonza

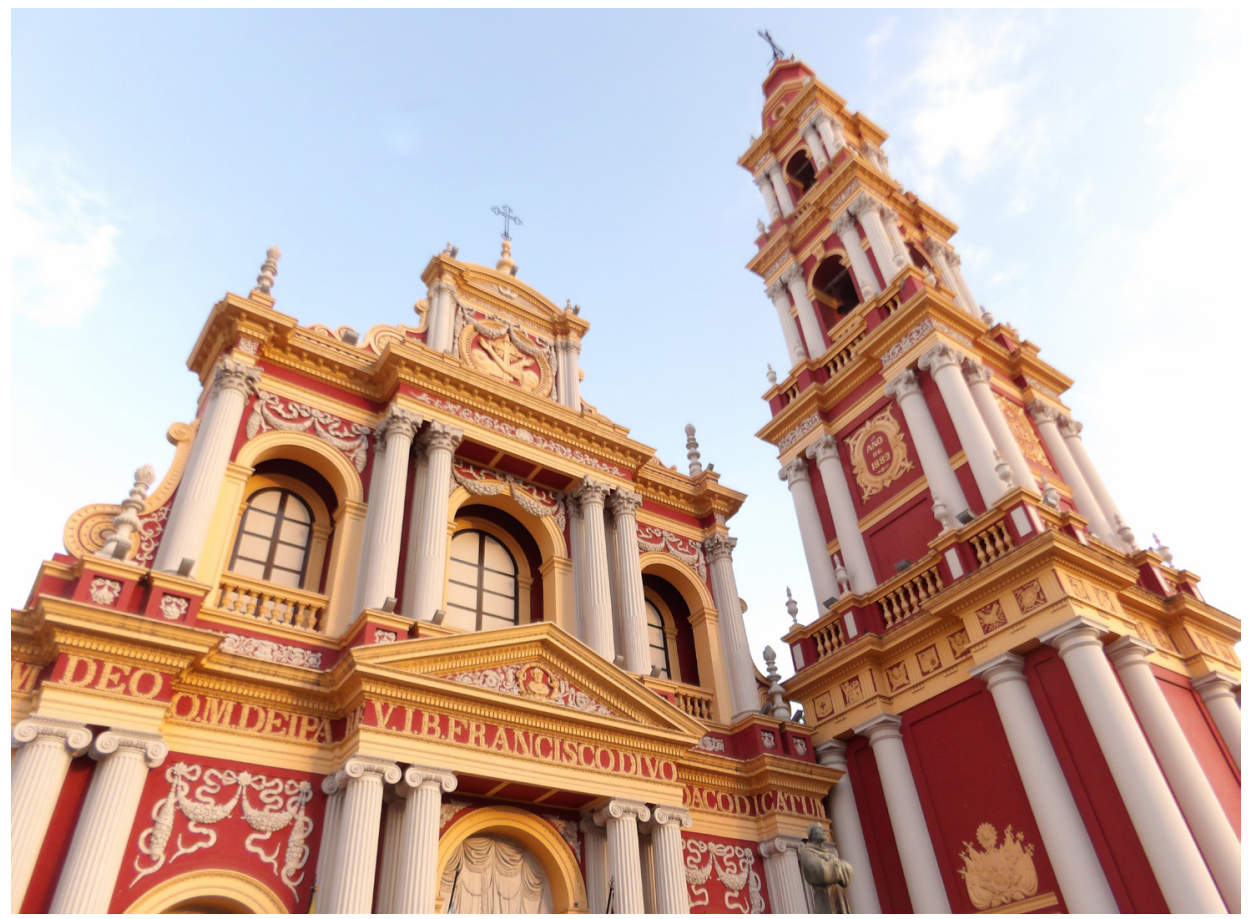

Figura 3. Iglesia San Francisco

Fotografía: Cinthia Natalia Gonza 
Durante el 2000 estos edificios fueron resaltados por las acciones del programa de Recuperación del Casco Histórico, lanzado durante la gestión del gobernador Juan Carlos Romero. El programa supuso la restauración, pintura e iluminación de la catedral, el Cabildo, el Convento de San Bernardo, el edificio de la Jefatura de Policía, etcétera es decir, aquellos edificios que orbitan alrededor la Plaza 9 de Julio. De esta manera el espacio del centro histórico refuerza su rol como lugar central de encuentro, paseos, entretenimiento, ocio, turismo, consumo. Estas acciones fueron acompañadas por la instalación de un equipamiento urbano que apuntó a recrear un tiempo pasado inspirado en la época colonial instalando farolas adosadas a las paredes que coronan muchas esquinas. Durante el 2011 también se instalaron cartelerías de inspiración colonial (de un material semejante a los mosaicos sevillanos) señalando los nombres que las calles tenían durante aquel periodo. Aquí también se reafirma cierta forma de recorrer el lugar, sugiriendo una interpretación del centro histórico como colonial, más allá de la conjunción de épocas y estilos que condensa el área urbana. La transformación se complementa con la ubicación en el espacio público de cestos, borlados, barreras de tránsito, faroles de pie y adoquines que refuerzan la idea de lugar histórico.

Las representaciones de la ciudad colonial dejan fuera de sus formas simbólicas - además de otros tiempos y formaciones arquitectónicas- cualquier referencia a las historias de las mujeres. Ni las plazas, ni los museos, ni los monumentos o ningún otro elemento de esa red constituida por el dispositivo del patrimonio histórico, incorporan la figura de la mujer, salvo bajo la fría silueta de yeso de la "madre" introducida por la iglesia católica, una de las representaciones más estancas en el tiempo. Se exalta, por el contrario, la figura del hombre como el sujeto fundante de la ciudad, guerrero gaucho protector, intelectual, político y bohemio. Son mínimas las referencias que se introducen sobre las mujeres en la ciudad y, en la escasez de los casos hacen referencia a la mujer criolla "hija de..." o "esposa de..." a partir de pequeñas placas de bronce.

Los dispositivos crean sujetos. Como mencionamos líneas arriba, la política pública de protección y creación de patrimonio en Salta, determina y legitima ciertos elementos que operan como referentes identitarios. Los argumentos de esta política pública sobre los beneficios de la asociación turismo y patrimonio generan consenso en tanto algo tan preciado como el patrimonio se encuentra protegido, resaltado y ofrecido a los visitantes, que tendrán la posibilidad de conocer la idiosincrasia local, de la cual los salteños "se sienten orgullosos" (Troncoso, 2013). La asociación entre identidad y patrimonio recurre aquí a cierta emotividad afectiva para lograr la legitimación de esta política turística y patrimonial. En este sentido, "se trata de poner en relieve cierto nivel en que la acción de quien gobierna es necesaria y suficiente" (Foucault, 2016, p. 87). 
Según el discurso del Gobierno de la provincia de Salta y el Ministerio de Cultura y Turismo, el incentivo a la visita turística no es el único motivo que explica las tareas de protección patrimonial. Se habla de acciones orientadas a la sociedad local y a la protección de sus referentes patrimoniales, más allá de su aprovechamiento turístico. El gobernador Juan Manuel Urtubey dijo al respecto que "reencontrarnos con nuestra cultura no debe ser solo marketing turístico, sino la manera de valorar nuestras raíces y sentirnos orgullosos de ellas" (Gobierno de la provincia de Salta, 2008).

El arquitecto Roque Manuel Gómez (2014) explica que la adhesión al movimiento del renacimiento colonial en Salta debe explicarse por su propia idiosincrasia, fuertemente conservadora y localista, orgullosa de su pasado, incondicionalmente apegada a su terruño en tanto exaltación nostálgica de lo propio, de la tradición, de lo regional. Para este arquitecto el estilo neocolonial se convirtió en un estado permanente y cotidiano que legitimaba una sociedad gaucha y heroica, noble y patricia, al mismo tiempo que legitima la permanencia de ciertas clases dirigentes (Gómez, 2014). Solo así puede explicarse que un lenguaje estético promovido por la generación radical porteña del Centenario fuese adaptado como norma por un gobierno conservador y fuera continuado por gobiernos posteriores justicialistas, liberales, populistas, prácticamente hasta la actualidad, constituyéndose en un poderoso vehículo de la transmisión de ideas y representaciones de valores que trascienden lo estrictamente arquitectónico para reflejar objetivos simbólicos sociales.

Los modos de organizar el espacio, la arquitectura, la importancia y la centralidad que se le confiere a ciertos lugares e instituciones, sus monumentos históricos y los modos de andar la ciudad, son el testimonio de una época o formación histórica que en su distribución legítima de lo visible y lo enunciable, coloca la figura del varón criollo en el centro del espacio público. El pasado colonial y la relevancia de Salta como lugar de partida de las expediciones contra los realistas comandadas por Güemes son rasgos de la historia local que se rescatan como referentes identitarios de los salteños y han estado vinculados con la idea de ciudad colonial, noble, patricia, cuna de la tradición, el folclor y celosa de este pasado. Aquí se introduce otra referencia de los efectos de verdad que produce el dispositivo del patrimonio histórico en Salta. Este efecto refiere a la capacidad de generar una convivencia "armónica" en el espacio, de referencias simbólicas que hacen alusión a dos momentos históricos incompatibles y en gran tensión. El gaucho, actor directo en las guerras por la independencia nacional, aparece como una figura simultánea en la ciudad colonial recreada. Así, la plaza Güemes (ubicada entre las calles Bartolomé Mitre, Leguizamón, Balcarce y Rivadavia), que debe su nombre al emblemático guerrero gaucho salteño, se encuentra coronada 
con el monumento a Hernando de Lerma, explorador y colonizador español del siglo xvi. Estas referencias diferentes, heterogéneas y dispersas se ligan y componen una figura "única", una especie de texto ininterrumpido en el espacio por el efecto del dispositivo (Foucault, 2016).

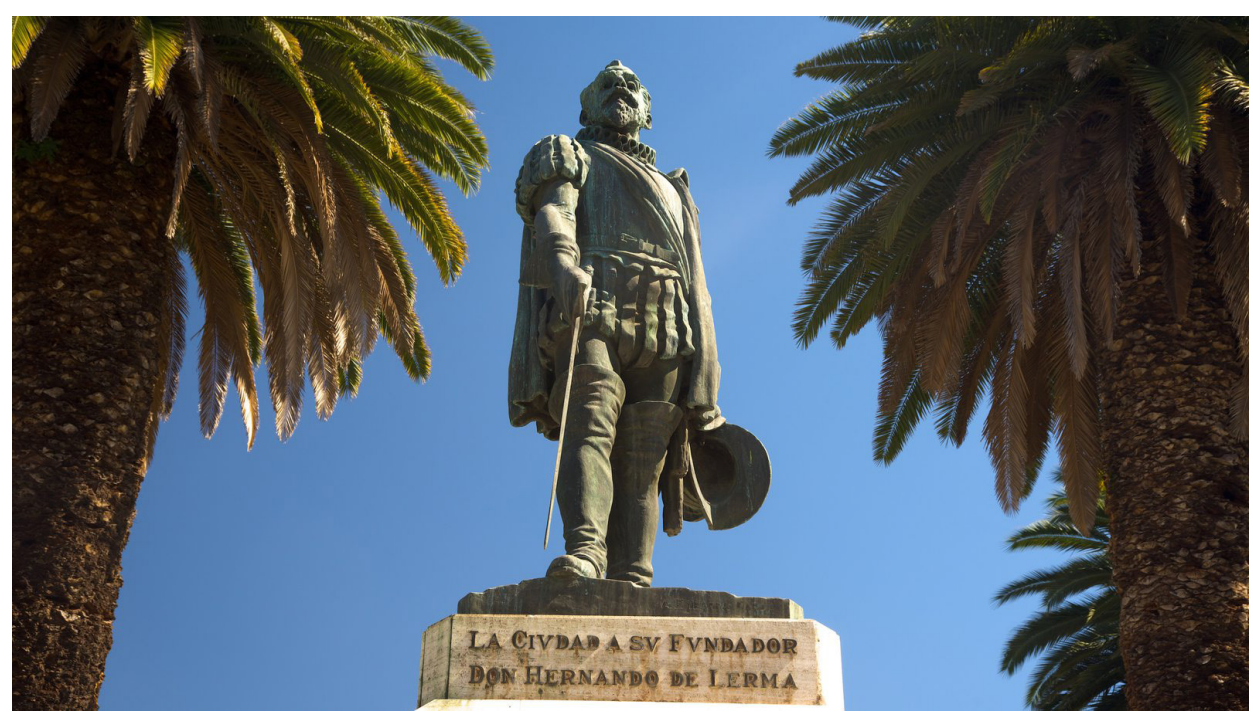

Figura 4. Monumento a Hernando de Lerma en Plaza Güemes Fotografía: Cinthia Natalia Gonza

\section{La fachada de los valores}

Las distintas marchas organizadas por los movimientos feministas constituyen una forma de problematizar esa red constituida por el patrimonio histórico de Salta. Desde el Encuentro Nacional de Mujeres que se llevó a cabo en octubre del 2014, la disputa por el uso y la significación del espacio quedó establecida. Días antes del Encuentro se reguló el recorrido de la marcha con la que año a año se cierra esta jornada. A raíz de una serie de demandas de grupos profesionales y acuerdos previos entre la comisión organizadora del encuentro con autoridades municipales, se estableció que la marcha no circularía por el principal circuito del casco histórico de la ciudad.

La asociación de Arquitectos en el Resguardo del Patrimonio del Centro de la Ciudad de Salta (COPAUPS), días antes de efectuarse el Encuentro Nacional de Mujeres, emitió una nota a la municipalidad en la cual se solicitaba lo siguiente:

Nos dirigimos a Uds., a fin de solicitarles tengan a bien tomar las medidas pertinentes y adecuadas para la Protección del Área Centro de la Ciudad de Salta en 
ocasión del Encuentro Nacional de Mujeres a realizarse en la Provincia de Salta los días 11, 12 y 13 de octubre del corriente año.

Desde hace muchos años los salteños venimos trabajando en pos de la salvaguarda de nuestro extenso patrimonio arquitectónico, urbano, natural y cultural. Una política de Estado que ha trascendido las facciones políticas y se ha extendido e incentivado desde el año 2008 con la aplicación efectiva de la Ley nº 7418 . Dicha decisión política ha sido acompañada por inversión pública concreta en obras de recuperación de edificios históricos como en el propio espacio público de calles y plazas, como así también en promoción turística a fin de lograr mantener, desarrollar y embellecer nuestro centro histórico que se ha convertido hoy en un ejemplo de gestión pública. Es necesario destacar que una de las actividades económicas más importantes de la provincia es el turismo cultural el cual tiene su producto principal en el área centro de la ciudad por su extenso patrimonio arquitectónico [...].

Por lo antes mencionado es que, conociendo las competencias de la Copaups en el Área Centro Declarada Bien de Interés de todos los salteños, solicitamos DISPONGA MEDIDAS de ORDEN y consecuente RESGUARDO del área centro de nuestra Ciudad de Salta para la realización de las Jornadas del Encuentro Nacional de Mujeres que se llevarán a cabo en nuestra Provincia los próximos 11 a 13 de Octubre [...]. (Salta, Asociación de profesionales preocupados por el patrimonio ante el Encuentro Nacional de Mujeres, 2014)

A pesar de los acuerdos y las peticiones de resguardo del patrimonio histórico de la ciudad por parte de ciertos sectores de la sociedad salteña, el día de la marcha una columna de mujeres logra recorrer aquellas calles resguardadas. Aun cuando la policía delimita el recorrido de la marcha protegiendo "el casco histórico del centro" (catedral, cabildo, museos y plaza principal), muchas mujeres hacen caso omiso a este señalamiento y logran desplazarse por aquellas calles que habían quedado fuera del circuito habilitado. Aquí la disputa por el espacio y sus sentidos es más clara. Mientras que la policía resguardó la catedral, la plaza principal y el espacio circundante, algunas columnas de la marcha se escabulleron para llegar allí y dejar una marca, un testimonio, una pintada, cantar, bailar - algunas con el torso desnudo- frente a la catedral. Esta contienda por el espacio y el sentido del mismo, terminó en un enfrentamiento físico entre la policía, algunos ciudadanos que intentaron resguardar la catedral y las activistas feministas.

Esto sucedió el día domingo 12 de octubre en Salta con un grupo de personas que se ubicaron frente a nuestra catedral con el fin de impedir el paso de estas mujeres y el destrozo hacia la misma ya que tenían toda la intención de pintar con graffitis usando palabras obscenas y agresivas hacia nuestra religión y nuestra creencia, no lograron cometer este incidente gracias a todos nuestros salteños que la protegieron, lástima que esto no sucedió en toda la provincia y destrozaron nuestra tranquilidad y nuestros lugares públicos dejando frases irreproducibles con 
aerosoles por todos lados, es una pena y una indignación hacia nuestra provincia. (¡Qué indignación! Encuentro Nacional de Mujeres en Salta, 2014)

En la ciudad de Salta las reivindicaciones sociales y las luchas políticas de las mujeres no pueden codificarse como tales. Los valores tradicionales que toman cuerpo de bronce y piedra en la ciudad solo reconocen la figura del hombre como agente político. Rindiendo culto a esa tradición, es menester que las mujeres conserven los espacios históricamente visibilizados y enunciados para ellas.

El patrimonio histórico de la ciudad de Salta, en tanto maquinaria del ver y el decir, arroja sombras sobre la participación de las mujeres en la esfera pública. Aun cuando estas juegan roles decisivos en situaciones de crisis, riesgo colectivo y en la vida cotidiana, las escasas referencias que este dispositivo ofrece de las prácticas, las experiencias y las historias de las mujeres reactualizan el estereotipo de estas en tanto sujetos física, intelectual y moralmente débiles, cuyos roles se circunscriben a la función de la maternidad y el cuidado de la familia y, por lo tanto, a sujetos ajenos a la actividad política y pública (Barrancos, 2007).

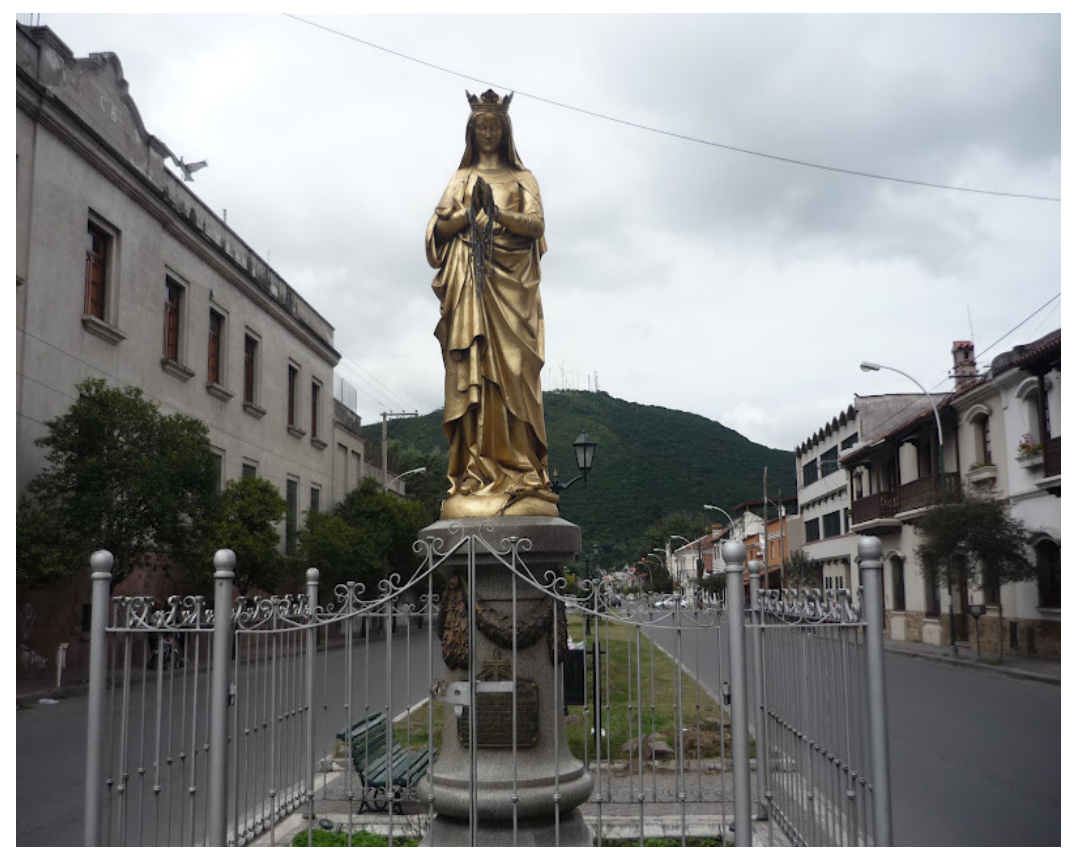

Figura 5. Virgen Inmaculada ubicada en calle Entre Ríos Fotografía: Cinthia Natalia Gonza 


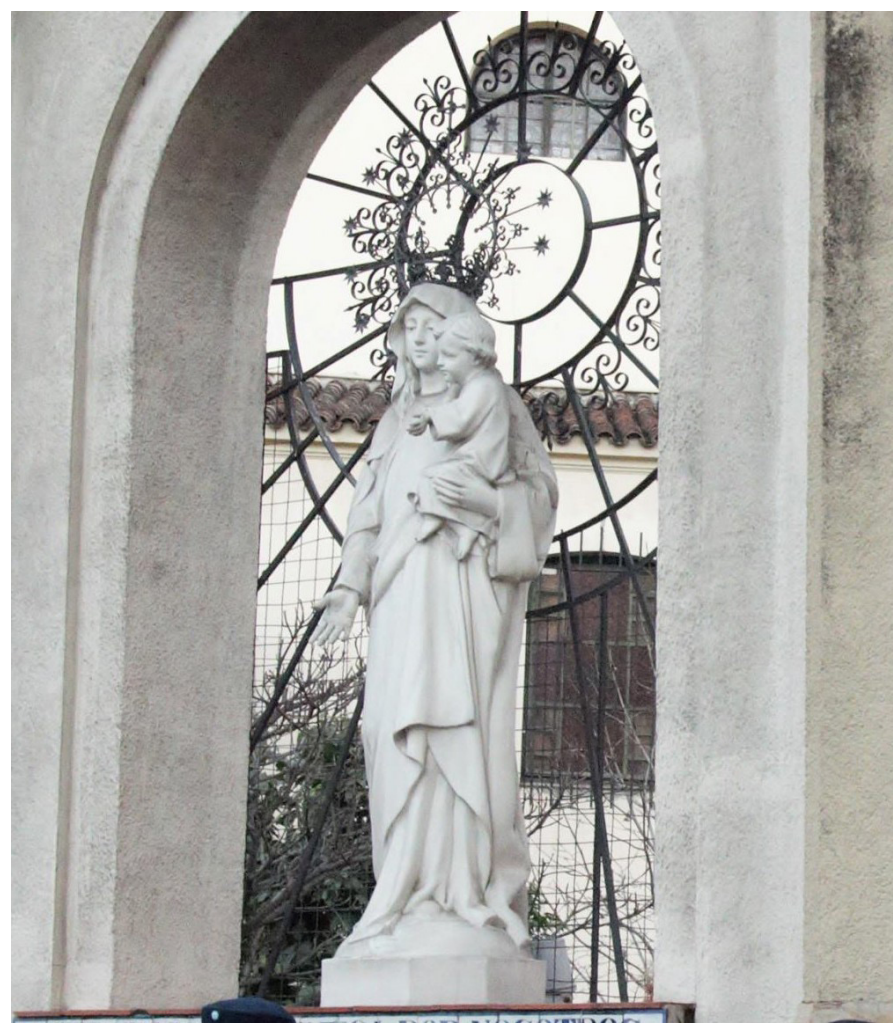

Figura 6. Virgen Reina de la Paz ubicada en calle Mitre Fotografía: Cinthia Natalia Gonza

Los efectos del ver y el decir aquí refuerzan la adscripción a roles fijos y al mismo tiempo aseguran la permanencia de ciertos estereotipos que, como ya se mencionó, asocian a la mujer con el rol de madre, esposa, ama de los cuidados. Estos estereotipos, a su vez, se expresan en representaciones geográficas binarias como espacio público-privado, oposiciones de matriz ideológica y no empírica.

El dispositivo del patrimonio arquitectónico se teje con aquellos relatos históricos de las ciudades hidalgas que ofrecen una imagen subordinada de las mujeres a pesar de que, como mencionamos en este artículo, su presencia y sus acciones componen un complejo entramado de relaciones y desplazamientos. José Luis Romero (2014) nos ofrece algunas referencias de las prácticas de las mujeres de la élite española en las ciudades coloniales y nos muestra cómo estas se encuentran en permanente negociación entre la esfera pública y privada:

Llegadas de España o hijas de conquistadores adquirieron la autoridad que les permitía su condición en la nueva sociedad. Fueron a veces encomenderas en los 
campos y La Quintrala² dio prueba en Chile de la férrea voluntad con la que eran capaces de defender sus derechos y propiedades. En las ciudades procuraron crear el ambiente de distinción propio de las cortes y las ciudades españolas, rodeadas de esclavos y de criados [...]. No faltaron ejemplos de la decisión de aceptar pesadas responsabilidades políticas como la viuda del gobernador de Bahía Jorge de Albuquerque, o la del gobernador de Guatemala Pedro de Alvarado. Pero su lugar estuvo en el ámbito de la casa noble y su preocupación fundamental fue consolidar y perpetuar la nueva hidalguía de la familia constituida en la India. Quizás podría decirse que al lado del varón aventurero tentado siempre por nuevas posibilidades que mejoraran más y más su hacienda o su condición social, la mujer estabilizó las familias de las ciudades y logró crearles una tradición que, en muy poco tiempo transformó a alguna de ellas en linaje aristocrático. (Romero 2014, p. 77)

También Dora Barrancos (2007) realiza una relectura histórica de la participación de las mujeres en asuntos públicos y políticos desde la época colonial hasta la década de 1990, y da cuenta de las distintas tácticas que las mujeres idearon para suspender o subvertir, al menos de formas momentáneas, las imposiciones del patriarcado.

Durante la época colonial las funciones de las mujeres se vinculaban con la maternidad y los cuidados de la familia, tareas incompatibles con las "rudas responsabilidades" del espacio público propias de hombres y, además, se extendía (aun incluso hasta el siglo XIx) la noción de "peligro" cuando se trataba de la identidad femenina en relación con el desempeño en actividades de carácter social y político que trascendían los límites domésticos (Barrancos, 2007); no obstante, las prácticas cotidianas de las mujeres españolas e hijas de españoles se hallan teñidas de matices y negociaciones implícitas tanto en las calles como en las casas nobles.

En esa dirección, de las primeras españolas que arribaron a nuestro territorio por el Río de la Plata, en la expedición que condujo a la fundación de Buenos Aires (1536), ha sobrevivido un testimonio singular que, aunque cuestionado en su autenticidad, narra acontecimientos que pudieron ser corroborados (Barrancos, 2007). Se trata de una carta escrita por Isabel de Guevara varios años después de los dramáticos episodios de la hambruna y las enfermedades que azotaron a la población de Santa María del Buen Ayre. Isabel escribió:

Vinieron los hombres con tanta flaqueza que todos los trabajos cargaban en las pobres manos de las mujeres, así en lavarles la ropa como en curarles, hacerles de comer lo poco que tenían, limpiarlos, hacer centinela, rodar los fuegos, armar las ballestas cuando a veces los indios venían a dar guerra [...] dar alarma por el

2 Catalina de los Ríos y Lisperguer, conocida como La Quintrala fue una aristócrata y terrateniente chilena de la época colonial. 
campo a voces, sargentando y poniendo en orden a los soldados. Porque en ese tiempo como las mujeres nos sustentamos con muy poca comida no habíamos caído en tanta flaqueza como los hombres. [...] Y si no fuera por la honra de los hombres, muchas más cosas escribiera con verdad y los diera a ellos por testigo. (cit. en Barrancos, 2007, p. 30)

La carta citada no solo constituye la primera crónica escrita por una mujer de aquel entonces; también ofrece un nuevo relato histórico sobre la participación de las mujeres españolas en la conformación del nuevo territorio colonial y muestra la diversidad de roles que estas asumieron en ese contexto. En contrapartida, el hombre conquistador aparece aquí como un sujeto débil, enclenque y asistido, retrato que dista mucho de la imagen heroica, robusta y determinante que muestran los monumentos históricos, los retratos en los museos y de los relatos oficiales.

La crónica de Isabel de Guevara es uno de los pocos relatos recuperados de la época, en donde una mujer escribe en primera persona pues, como bien señala Barrancos:

Debe lamentarse que sea casi inexistente las voces femeninas escritas en primera persona en la escritura de los primeros siglos coloniales, no sólo por el obstáculo del analfabetismo, sino también porque es sabido que las cartas de las mujeres estaban expuestas a mayores riesgos de destrucción. Los archivos sobrevivientes redundan en registros masculinos - sacerdotes, jueces, corregidores - indiscutibles portavoces de las mujeres. (2007, pp. 31-32)

Es por esta razón que la voz masculina se constituye como relato hegemónico de la época y este buscó vislumbrar los ángulos consabidos de la "naturaleza femenina" vinculados a la pasividad, la sumisión y la ternura. Bien retrata a esta mujer el holandés Azcarate de Biscay en 1658: "Las mujeres eran extremadamente bellas, de cutis terso y bien formadas, y en cuanto a las mujeres casadas, eran sumamente fieles, pues no había tentación posible que las hiciera faltar a sus deberes" (cit. en Barrancos, 2007, p. 27).

Aun cuando las mujeres de aquel entonces protagonizaran movilizaciones, la voz masculina las banalizó. A mediados de 1700 las religiosas catalinas iniciaron una revuelta en la ciudad de Buenos Aires tras la sustitución de sus confesores jesuitas por mercedarios. Esta revuelta fue descrita por el "obispo Manuel Antonio de la Torre como una 'mujeril revolución como la que sucede en el espanto de las gallinas encerradas en el gallinero'" (cit. en Barrancos, 2007, p. 39).

En la ciudad de Salta encontramos algunas referencias interesantes en la transición entre la época colonial a la poscolonial. Es la escritora Juana Manuela Gorriti (1818-1892), a quien se deben los pocos relatos que dan cuenta de aquellas prácticas llevadas adelante por mujeres, que lograron condensar las esferas disociadas pública-privada y, al mismo tiempo, brindar relatos de otros tipos de feminidades. 
Bajo la pluma de esta escritora salteña se delinea el perfil de Juana Azurduy, guerrera independentista de la región norandina del país. Nacida en Chuquisaca, Bolivia (por entonces parte del Virreinato del Río de la Plata) en 1781, esta mestiza se escapó del convento en donde se educaba para casarse con el militar Manuel Ascencio Padilla en 1805. Junto a su esposo, Juana se une a las tropas de Manuel Belgrano en apoyo a la causa independentista, guiando sus propias legiones de hombres ("Los Leales") y mujeres ("Las Amazonas"). Tras la muerte de Padilla en 1816 en la Batalla de La Laguna, ella continúa al mando de sus tropas en el Noroeste argentino, donde se une al General Martín Miguel de Güemes y conoce a la entonces niña Juana Manuela Gorriti. El hecho de que Juana Azurduy desempeñara funciones poco usuales para su género en el siglo XIX, despertó diversas opiniones en la época que destacaron cierto carácter "antinatural" en sus acciones (Miseres, 2017).

La figura militar femenina fue enrarecida y masculinizada y, mediante esta operación, se destacó la no-pertenencia de la mujer al ámbito de la guerra. Así, el militar Antonio Beruti le escribe a Belgrano haciendo referencia al "varonil esfuerzo y bizarría de la Amazona doña Juana Azurduy" (Davies, Brewster y Owen, 2006, p. 140).

Por otra parte, la escritura de Juana Manuela Gorriti resulta fundamental para entender la dinámica de las mujeres en y con el espacio durante la época colonial y poscolonial. En sus numerosos relatos de guerras y conflictos armados en la región de Salta y en el Perú, el espacio simbólico y físico del hogar o casa familiar está lejos de representar un ámbito opresivo para las mujeres. En tiempos de guerra, las casas de Gorriti son espacios abiertos y activos políticamente que se transforman, en el presente de la narración, en lugares productivos para su memoria y escritura.

Son estos relatos, estos personajes guerreros e intelectuales los que no aparecen en las referencias simbólicas de la ciudad. El actual patrimonio arquitectónico e histórico de la ciudad de Salta destaca de la ciudad colonial que recrea y reproduce la simulación entre el espacio público y el espacio privado como esferas claramente separadas, producto de las relaciones de poder erguidas sobre la ideología patriarcal. Por ello, la presencia de referencias de materialidad simbólica en torno a las mujeres se reduce a la imagen de la virgen madre. Parte del entramado de relaciones de poder a las cuales se alude, se materializa en el patrimonio arquitectónico de la ciudad, y este, a su vez, es destacado y revitalizado en tanto símbolo de los valores tradicionales de la identidad salteña colonial. El patrimonio arquitectónico histórico compone entonces un vehículo para la transmisión de ideas y representaciones de valores que trasciende lo estrictamente arquitectónico y expresa objetivos simbólicos sociales. Por su parte, la tradición 
funciona aquí como un medio que justifica las relaciones de poder y de exclusión y/o anulación de las diferencias.

\section{Conclusiones}

Podría decirse que el dispositivo del patrimonio arquitectónico e histórico de Salta, en tanto conjunto de herramientas y estrategias programadas, produce el efecto de verdad de "Salta, ciudad colonial" y, en la compleja red de articulaciones que propone con elementos históricos, culturales, sociales, económicos y políticos, tiene la capacidad de captar, orientar, determinar, modelar, controlar, los gestos, las conductas, las opiniones y los discursos en la ciudad. Al mismo tiempo logra condensar una serie de elementos heterogéneos y dispersos en la ciudad y presentarlos como un texto ininterrumpido que hace convivir de forma armónica y descontextualizada a la ciudad gaucha-criolla con la ciudad colonial, como así también logra sintetizar elementos de la arquitectura barroca italiana como parte del estilo arquitectónico colonial.

El análisis de alguno de estos elementos constituye una lente posible a la hora de mirar la desigualdad en el acceso y en el uso de la ciudad por parte de hombres y mujeres. La comprensión del patrimonio histórico como un dispositivo de enunciados y visibilidades que opera al mismo tiempo como un umbral de etización, estetización y politización (Deleuze, 2015, p. 79), permite entender parte de las relaciones de un poder patriarcal que condicionan la concepción de la ciudad y hacen una apropiación diferenciada de esta.

En esta relación que establece luces y sombras, voces, susurros y silencios, las referencias simbólicas materiales de mujeres se encuentran limitadas y condicionadas por la representación de la mujer que ofrece la tradición cristiana y que orbita en torno a la pureza, la castidad, la devoción y la maternidad. Estas condiciones refuerzan la adscripción a roles fijos entre hombres y mujeres asegurando la permanencia de los estereotipos que asocian a la mujer con el rol de madre, esposa, ama de los cuidados. Al mismo tiempo, estos estereotipos y roles estancos se expresan en representaciones geográficas binarias como espacio público-privado, oposiciones de matriz ideológica que ordena (idealmente) los cuerpos de las mujeres en el ámbito doméstico y los cuerpos de los varones en el espacio público.

La ciudad entendida como un estrato o formación histórica, capa sedimentaria hecha de cosas y de palabras, de ver y de hablar, de lo visible y lo decible, será un lugar de disputa de sentido que, al mismo tiempo que lo produce y reproduce dentro de relaciones de poder, admitirá y legitimará unos, omitirá y deslegitimará otros. 
Por ello la presencia de las mujeres en el espacio público en las distintas manifestaciones feministas constituye una forma de problematizar el patrimonio histórico de Salta. Es en este contexto donde las manifestantes logran plasmar sobre la fachada del patrimonio arquitectónico una nueva materialidad simbólica y política que pone en jaque el estereotipo de la mujer en la "Salta colonial". Aun cuando estas prácticas no sean registradas ni reconocidas como estrategias políticas y sus demandas sociales no sean codificadas como tales, la mera presencia de estos cuerpos que recorren, interpretan e interpelan al espacio de forma diferente da cuenta de los permanentes desplazamientos que estas efectúan entre las esferas públicas y privadas y la inestabilidad de las mismas.

\section{Referencias}

Agamben, G. (2016). Qué es un dispositivo. Buenos Aires: Editorial Adriana Hidalgo.

Barrancos, D. (2007). Las mujeres en la sociedad argentina. Una historia de cinco siglos. Buenos Aires: Editorial Sudamericana.

Boletín Oficial Salta. (2006). Ley N. 7418 Protección del Patrimonio Arquitectónico y Urbanistico de la Provincia de Salta. Recuperado de http://www. boletinoficialsalta.gob.ar/VersionImprimibleLeyes.php?nro_ley2=7418

Davies, C., Brewster, C., y Owen, H. (2006). South American Independence: Gender, Politics, Text. Liverpool: Liverpool University Press.

Deleuze, G. (2015). Foucault. Buenos Aires: Paidós.

Flores Klaric, M. (2010). De la representación del salteño y sus tradiciones en la construcción de los primeros discursos del turismo (1910-1945). En Álvarez Leguizamón S. (Ed.), Poder y salteñidad. Saberes, politicas y representaciones sociales. Salta: Editorial CEPHIA, Facultad de Humanidades, pp. 51-68.

Foucault, M. (1987). El orden del discurso. Barcelona: Tusquets.

Foucault, M. (2016). Seguridad territorio y población. Buenos Aires: Fondo de Cultura Económica.

Foucault, M. (2018). La arqueología del saber. Buenos Aires: Siglo XXI Editores.

Gobierno de la provincia de Salta, (2008). Reencontrarnos con nuestra cultura no es sólo marketing turístico, dijo Urtubey. Ministerio de Turismo y Cultura. Recuperado de http://www.salta.gov.ar/prensa/noticias/reencontrarnoscon-nuestra-cultura-no-es-solo-marketing-turistico-dijo-urtubey-/140

Gómez Roque M. (2014). El neocolonial o la construcción del imaginario en Salta. Salta: Fondo Editorial Secretaría de la Cultura de la Provincia de Salta.

McDowell, L. (2000). Género, identidad y lugar. España: Cátedra. 
Miseres, V. (2017). Mujeres en tránsito. Viaje, identidad y escritura en Sudamérica (1830-1910). Chapel Hill: University of North Carolina.

¡Qué indignación! Encuentro Nacional de Mujeres en Salta. (2014). TN y la Gente. Recuperado de https://tn.com.ar/tnylagente/que-indignacion-encuentronacional-de-mujeres-en-salta-2014_536454

Romero, J. L. (2014). Latinoamérica. Las ciudades y las ideas. Buenos Aires: Siglo XXI Editores.

Salta. Asociaciones de profesionales preocupadas por el patrimonio arquitectónico ante el Encuentro Nacional de Mujeres (2 de octubre del 2014). El Intransigente. Recuperado de https://www.elintransigente.com/salta/2014/10/2/saltaasocia ciones-profesionales-preocupadas-patrimonio-arquitectonico-anteencuentro-nacional-mujeres-269664.html

Soto Villagrán, P. (2011). La ciudad pensada, la ciudad vivida, la ciudad imaginada. Reflexiones teóricas y empíricas. La Ventana, 4(34), pp. 7-38. Recuperado de http://www.scielo.org.mx/pdf/laven/v4n34/v4n34a3.pdf

Troncoso, C. (2013). Política turística y patrimonio en la ciudad de Salta. Estudios y perspectivas en turismo 22(6), pp. 1002-1024. Recuperado de http://www. scielo.org.ar/scielo.php?script=sci_arttext\&pid=S1851-17322013000600001 